УДК 338.242.2

Бакаева В.В.

ФГБОУ ВО «Новосибирский государственный педагогический университет», Новосибирск, e-mail: vbakaeva@yandex.ru

Красильникова Т.В.

ФГБОУ ВО «Новосибирский государственный педагогический университет», Новосибирск, e-mail: kiahwe@gmail.com

ОЦЕНКА КОНКУРЕНТОВ

ОБРАЗОВАТЕЛЬНОЙ ОРГАНИЗАЦИИ ВЫСШЕГО ОБРАЗОВАНИЯ МЕТОДОМ АНКЕТНОГО ОПРОСА

Ключевые слова: высшее образование, вузы, университеты, конкуренты, конкурентные преимущества, методы определения конкурентов, опрос обучающихся как метод определения конкурентов, рейтинг вузов-конкурентов.

Исследования конкурентов в сфере высшего образования нацелены на разработку решений в образовательном менеджменте, основываясь на данных и наличии конкурентов среди вузов, образовательных программ. Важно корректно оценить и последовательно усиливать собственные конкурентные преимущества вуза, либо последовательно снижать конкурентные риски, вовремя предпринимать соответствующие усилия на конкурентном и рыночном поле современного высшего образования. В статье представлены результаты анкетного опроса первокурсников, поступивших на направления подготовки по экономике, менеджменту, рекламе. Эти образовательные программы реализуются несколькими вузами Новосибирска, конкурирующими между собой по многим факторам, включая известность, уровень обеспечения образовательного процесса, доступность для обучения иногородних студентов, ценовые параметры обучения. Интерпретация данных проведена с позиции рейтинга конкурентов по отношению к одному из вузов, реализующему названные образовательные программы бакалавриата. Отмечена необходимость глубинных оценок мотивации выбора вуза абитуриентами в разрезе отдельных направлений подготовки в целях многофакторных оценок конкурентных преимуществ университетов с последующим ранжированием факторов.

\title{
Bakaeva V.V.
}

Novosibirsk State Pedagogical University, Novosibirsk, e-mail: vbakaeva@yandex.ru

Krasilnikova T.V.

Novosibirsk State Pedagogical University, Novosibirsk, e-mail: kiahwe@gmail.com

\section{ASSESSMENT OF COMPETITORS \\ OF THE EDUCATIONAL ORGANIZATION \\ OF THE HIGHER EDUCATION BY THE QUESTIONNAIRE METHOD}

Keywords: the higher education, higher education institutions, universities, competitors, competitive advantages, methods of definition of competitors, poll of students as method of definition of competitors, rating of rival higher education institutions.

Researches of competitors in the sphere of the higher education are aimed at development of decisions in educational management, based on data and presence of competitors among higher education institutions, educational programs. It is important to estimate correctly and to consistently increase own competitive advantages of higher education institution, or to consistently reduce competitive risks, in time to make the corresponding efforts on the competitive and market field of modern higher education. Results of questionnaire of the first-year students who arrived on the directions of preparation on economy, management, advertizing are presented in article. These educational programs are implemented by several higher education institutions of Novosibirsk competing among themselves on many factors including popularity, level of ensuring educational process, availability to training of nonresident students, price parameters of training. Interpretation of data is carried out from a position of rating of competitors in relation to one of higher education institutions implementing the called educational programs of a bachelor degree. Need of deep estimates of motivation of the choice of higher education institution by entrants in a section of the separate directions of preparation for multiple-factor estimates of competitive advantages of the universities with the subsequent ranging of factors is noted. 


\begin{abstract}
Введение
Проблема выбора будущей профессии выпускником школы актуальна не только с позиции сложности выстраивания индивидуальной образовательной траектории, но и находится в плоскости социально-экономической модели образовательного поведения будущего студента. С одной стороны, очевидны нерешенные вопросы профессиональной ориентации школьников, противоречия и неясности в их самоопределении, необходимость выбора на этапе подготовки к ЕГЭ конкретного вуза из имеющихся альтернатив. С другой стороны - выбор профессии и ориентиров будущей карьеры становятся для вчерашнего школьника выбором доступного вуза. На этот выбор влияет ряд факторов, важнейшими из которых являются качество информационной и коммуникационной политики вуза, его ценовая и даже транспортная доступность для будущего студента. Сюда же относятся особенности образовательного процесса и дополнительные услуги, которые позволяют расширить спектр компетенций выпускника.
\end{abstract}

В условиях неблагоприятных вызовов внешней среды все чаще возникает ситуации, когда факт поступления вчерашнего школьника в тот или иной вуз есть результат выбора, совершенного в условиях неопределенности им самим и/или членами его семьи путем сравнения разных вариантов по параметрам, определяемым названными выше факторами.

Эта новая модель социализации молодых людей, существенно отличается от традиционной, базировавшейся на «самоценности» образования. В ней также практически не осталось упоминаний о трудовых династиях. И мало, кто из нынешних первокурсников вузов назовет в качестве причины поступления тот факт, что «с детства хотел стать менеджером». Добавим, что и большинства нынешних профессий в прошлом старшего поколения просто не было. Современное информационное пространство, в котором сосредоточены множественные проявления образовательных векторов и траекторий для молодого поколения, как может показаться на первый взгляд, сглаживает до исчезновения этапы карьеры и получения профессии, создавая иллюзию легкости, везения, эмоциональной окрашенности происходящего [1]. Между тем, неравномерно, зачастую консервативно, чересчур масштабно, или, напротив, узко и невыразительно, формируется медиа-мышление вуза. Представить себя достойно среди равных, донести до пользователей информацию так, чтобы модель выбора вуза абитуриентом стала завершенной - непростая задача. Какие вузы представлены в когорте выбора абитуриента, и является ли этот выбор вообще конкурентным? Сегодня стоит задача сформировать действенные инструменты информационного взаимодействия между вузом (или на уровне структурного подразделения университета - факультета, института) и школьниками. В конечном счете, индивидуализировать, усилить приемную кампанию. Успешность приемных кампаний - залог стабильности ресурсного обеспечения образовательной деятельности, а для «платных» факультетов - ресурс финансовой стабильности.

\section{Цель исследования}

Исследования конкурентов в сфере высшего образования ориентированы на получение широкого спектра данных, оцениваемых количественно и качественно с позиции назначения формируемых сведений. В том числе:

- наличие конкурентов среди образовательных организаций;

- наличие конкурентов по направлениям подготовки, по уровням, формам обучения;

- собственные конкурентные преимущества образовательной организации;

- конкурентные преимущества вузов, ведущих подготовку по аналогичным направлениям подготовки;

- факторы «слабости» конкурентов и образовательной организации и др.

Поиск, обобщение, интерпретация и анализ информации по каждому из направлений конкурентных исследований требуют значительных усилий, которые, в свою очередь, обусловлены требованиями к обработке данных с использованием стандартизированных, не требующих специального инструментального и программного обеспечения методик и пригодностью расчетных данных к представлению пользователям информации. 
Количественные исследования конкурентов включают мониторинг следующих параметров: направлений подготовки и образовательных программ, стоимости обучения; уровня обеспечения образовательного процесса и др. Дополняют и позволяют провести качественный анализ результатов мониторинга опросы, в том числе, студентов-первокурсников.

Исследования факторов выбора вуза, сложности принятия решения о поступлении в конкретный университет, уровня осведомленности и ориентированности абитуриентов в предложениях вузов, методик оценки информационной насыщенности приемных кампаний эти и другие вопросы представлены в публикациях разных авторов $[1,2,3]$.

\section{Материал и методы исследования}

Анкетный опрос как метод количественных исследований направлен на получение численных показателей по изучаемому кругу вопросов от достаточного числа респондентов для их последующей интерпретации - оценок, ранжирования факторов, значимых для респондента и/или для организации, и в целях достижения наилучшей управляемости развитием фактора в будущем.

При изучении конкурентов вуза (с целью формирования эффективной конкурентной политики) в октябре 2017 года по итогам приемной кампании был проведен сплошной письменный анкетный опрос студентов Новосибирского государственного педагогического университета (НГПУ), зачисленных на образовательные программы, реализуемые институтом менеджмента и социальных коммуникаций (ИМиСК, до 01.03.2018 институт рекламы и связи с общественностью, ИРСО) ${ }^{1}$. Опрашивались студенты 1 курса следующих направлений:

- 38.03.01 Экономика (один профиль подготовки);

- 38.03.02 Менеджмент (три профиля подготовки);

- 42.03.01 Реклама и связи с общественностью (один профиль подготовки).

Пригодными для обработки оказались 62 анкеты с распределением ответов между 67,7\% девушек и 33,3\% юношей. Вопросы касались единственности

${ }^{1}$ Обучение в ИМиСК осуществляется на контрактной основе, с полным возмещением затрат. или альтернативности выбора вузов для поступления (с указанием университетов, куда подавались документы, либо было желание поступать), выбора направления подготовки, специалитета для поступления, источников информации, из которых стало известно о данном институте и др.

\section{Результаты исследования}

По итогам опроса около 81\% первокурсников отметили, что кроме ИРСО (НГПУ) рассматривали возможность поступления в другие вузы г. Новосибирска. В том числе, хотели поступать в вузы других регионов Сибирского Федерального округа (Барнаула, Томска, Красноярска, Кемерово) 11,3\% опрошенных. Рассматривали вариант обучения в Москве, Санкт-Петербурге, Калининграде только четверо $(6,5 \%)$, что указывает, скорее всего, на присущий данным респондентам «романтизм» в оценке своих образовательных потребностей и не полное соотнесение их со своими возможностями.

В таблице представлен перечень альтернативных образовательных организаций, указанных в анкетах, а также рейтинг каждого из них по частоте упоминания.

В среднем в выборе первокурсников, указавших, что кроме ИРСО (НГПУ) они думали о поступлении в другие университеты, присутствуют два вуза, и альтернативность выбора укладывается в рамки простой модели - «один из трех». Какое именно место в приоритетности выбора занимал на момент поступления ИРСО (НГПУ), в ходе проведенного опроса не выяснялось, и здесь важным представляется аналогичный мониторинг мнений абитуриентов в момент приемной кампании. Согласно его результатам, первые места итогового рейтинга конкурентов ИРСО (НГПУ) занимают НГУЭиУ, СИУ РАНХиГС и НГТУ. При этом НГУЭиУ и СИУ РАНХиГС реализуют направления подготовки бакалавров «Экономика», «Менеджмент», «Реклама и связи с общественностью», а НГТУ фигурировал в ответах вчерашних абитуриентов и по названию факультета - «Факультет бизнеса», конкурируя в выборе между менеджментом, экономикой и психологией, юриспруденцией, и даже управлением качеством. 
Сводные данные упоминания вузов для поступления первокурсниками ИРСО (НГПУ)

\begin{tabular}{|c|c|c|c|}
\hline Образовательная организация & $\begin{array}{l}\text { Кол-во } \\
\text { ответов }\end{array}$ & $\begin{array}{l}\text { Уд. вес, } \\
\%\end{array}$ & Рейтинг \\
\hline 1 & 2 & 3 & 4 \\
\hline $\begin{array}{l}\text { НГУЭиУ (Новосибирский государственный университет экономи- } \\
\text { ки и управления) }\end{array}$ & 12 & 24,0 & 1 \\
\hline $\begin{array}{l}\text { СИУ РАНХиГС (Сибирский институт управления Российской ака- } \\
\text { демии народного хозяйства и государственной службы при Прези- } \\
\text { денте РФ) }\end{array}$ & 10 & 20,0 & 2 \\
\hline НГТУ (Новосибирский государственный технический университет) & 9 & 18,0 & 3 \\
\hline НГУ (Новосибирский государственный университет) & 8 & 16,0 & 4 \\
\hline СГУПС (Сибирский государственный университет путей сообщения) & 7 & 14,0 & 5 \\
\hline $\begin{array}{l}\text { СибГУТИ (Сибирский государственный университет телекоммуни- } \\
\text { каций и информатики) }\end{array}$ & 7 & 14,0 & 5 \\
\hline $\begin{array}{l}\text { Другие вузы г. Новосибирска: } \\
\text { НВВКУ (Новосибирское высшее военное командное училище) } \\
\text { НВИ(Новосибирский военный институт войск национальной гвардии) } \\
\text { НГАУ (Новосибирский государственный аграрный университет) } \\
\text { НГПУ (Новосибирский государственный педагогический универ- } \\
\text { ситет, без ИРСО) } \\
\text { НГТИ (Новосибирский государственный театральный институт) } \\
\text { НГУАДИ (Новосибирский государственный университет архитек- } \\
\text { туры, дизайна и искусств) } \\
\text { СГУВТ (Сибирский государственный университет водного транс- } \\
\text { порта, Новосибирск) } \\
\text { СГУГиТ (Сибирский государственный университет геосистем и } \\
\text { технологий) } \\
\text { СибУПК (Сибирский университет потребительской кооперации) }\end{array}$ & 16 & 32,0 & 6 \\
\hline $\begin{array}{l}\text { Другие вузы, расположенные не в г. Новосибирске: } \\
\text { РЭУ (Российский экономический университет имени Г. В. Плехано- } \\
\text { ва, Москва) } \\
\text { ЗБФУ (Балтийский федеральный университет им. И. Канта) } \\
\text { АГУ (Алтайский государственный университет, Барнаул) } \\
\text { КемГИК (Кемеровский государственный институт культуры) } \\
\text { СпбГУ (Санкт-Петербургский государственный университет) } \\
\text { ТГУ (Томский государственный университет) } \\
\text { СФУ (Сибирский федеральный университет) }\end{array}$ & 11 & 22,0 & 7 \\
\hline ИТОГО & 80 & 100,0 & - \\
\hline
\end{tabular}

В выборе студентов-рекламистов из представленных в таблице вузов фигурировали 7 новосибирских и 2 иногородних университета. Около 70\% опрошенных студентов первого курса направления «Реклама и связи с общественностью» если и рассматривали для себя обучение в другом вузе, то по аналогичному направлению. Скорее всего, это свидетельствует об изначально сформированной установке на обретение профессии, к которой абитуриент, как ему кажется, имеет склонность и которая будет перспективна в плане будущего трудоустройства. При этом можно предположить, что четкого представле- ния о необходимых профессиональных компетенциях у первокурсников нет, и опрошенные рассчитывают обрести ясность в процессе обучения.

Вузы, лидирующие в рейтинге упоминания, составляющие ядро конкурентов ИРСО (НГПУ), имеют богатую историю, стабильны в своей работе, находятся вблизи станций метро и доступны для проезда различными видами транспорта, что выступает немаловажным фактором для абитуриентов и их родителей. Например, НГУЭиУ - это знаменитый новосибирский «нархоз». Данное расхожее наименование университета по сути является визитной карточкой и отража- 
ет преемственность многолетней подготовки кадров для экономики региона. В отличие от него, бывшая Сибирская академия государственной службы, а ныне СИУ РАНХиГС при Президенте РФ, имеет особый статус образовательной организации, где «куют кадры» для государственного управления. Обучение здесь относительно дорогое, но «пропуск» в сферу, именуемую в общем виде «власть», требует заведомо больших ресурсов. Высшее образование - весомый, формируемый годами, прочный стереотип социального лифта, разрушать который, сиюминутно перечеркнув ценность образования, по меньшей мере, нерационально. А вопрос «добавленной ценности» и реального вклада полученного образования и складывающейся успешной или не очень успешной карьеры относится далеко не к утверждению, что экономисты и юристы в таком количестве нам не нужны.

Новосибирский государственный университет (НГУ) в ответах первокурсников фигурирует двояко. С одной стороны, $23 \%$ студентов-рекламистов рассматривали его по трем техническим специальностям от машиностроения до математического моделирования, что выглядит весьма странно, поскольку перечень вступительных испытаний на столь разные направления бакалавриата не совпадает. Гораздо более традиционно упоминание НГУ в контексте экономики, менеджмента, психологии, естественнонаучных специальностей.

Столь разный набор «вторых» в очереди приоритетов для поступления, и на фоне высокого конкурса (высокой стоимости обучения по направлениям аналогичным ИРСО) в НГУ, позволяет очертить, начиная с данного вуза, второй «пул» конкурентов. Его образуют СГУПС И СибГУТИ. Это вузы, которые, прежде всего, предлагают для поступления множественные альтернативы направлений подготовки и образовательных программ. Они являются отраслевыми университетами, занимающими особое место в истории Новосибирска, их выбор абитуриентами также связан с крепким и стабильным положением РЖД и Россвязи. В альтернативах для поступления первокурсниками назывались, как аналогичные ИРСО направления подготовки, так и специальности, связанные с защитой информации (СибГУТИ), юриспруденцией (СГУПС) и однократно - с управлением персоналом (также СГУПС). При этом СГУПС имеет более высокую стоимость обучения по сравнению с ИРСО (НГПУ). Эти два вуза замыкают пятерку рейтинга упоминания конкурентов, выявленных в ходе анкетирования.

Среди вузов Новосибирска, указываемых респондентами без привязки к направлениям подготовки ИРСО (НГПУ), а значит рассматриваемым как альтернативы обучения, назывались два двоенных вуза - НВИ и НВВКУ, Новосибирский государственный театральный институт (театральное искусство), СибУПК (товароведение) и ряд других вузов, имеющих в среднем по одному упоминанию. Данные университеты и институты объединены в шестую группу конкурентов, занимающих слабую позицию по отношению к рассматриваемому вузу и анализируемым направлениям бакалавриата.

\section{Выводы}

Проведенный опрос, показал, что выбор респондентов, поступивших в итоге на направления «Экономика» и «Менеджмент», отличался изначально значительной вариабельностью, в том числе в разрезе профилей. Например, в ответах студентов о предпочитаемом направлении встречается «бакалавриат по экономике», но по каким-то причинам они поступили на менеджмент. На каком этапе их выбор изменился, что повлияло на эту существенную перемену, и, главное, не испытывают ли первокурсники дискомфорта и/или чувства несамостоятельности, незавершенности собственного, по сути, первого взрослого решения?

В то же время, первокурсники-рекламисты по большей части демонстрируют более осознанный выбор, и в $69 \%$ случаев их выбор произошел в рамках единственного направления подготовки - «Рекламы и связей с общественностью». Около 85\% опрошенных данного направления осуществляют поиск вузов в пределах Новосибирска. Почему именно так, осталось невыясненным. 
Ответы на эти и другие вопросы требуют углубленных исследований, дополненных методами глубинных интервью, фокус-групп. Ключевое значение здесь приобретает фактор времени. Достоверность подобных опросов определенно выше, когда в памяти респондентов сохранились эмоции, связанные с нелегким выбором, и нет искажений, обусловленных изменившимся укладом жизни вчерашнего школьника.

Грамотная интерпретация индивидуальных и групповых интервью, составление точного инструментария, его апробация, позволят приблизиться к решению насущных проблем вузов, поставленных в ситуацию «внебюджетных» отношений, ведущих обучение на условиях полного возмещения расхо- дов студентами (заказчиками обучения). Речь идет о необходимых изменениях в коммуникационных решениях приемной кампании, неравенстве информационной составляющей кампании для «родственных» направлений бакалавриата: экономики и менеджмента, рекламы и журналистики, сервиса и туризма и др. Осмысления и изменения требуют и коммуникативные стандарты приемной кампании - «язык» общения с абитуриентом, представляющим сегодня образец так называемого клипового мышления и удержание внимания которого представляется, порой, неразрешимой задачей. Не случайно ни один из опрошенных первокурсников не смог вспомнить, что в его школе были встречи с представителями вузов.

Библиографический список

1. Онипко А.А. Противоречия самоопределения современных школьников // Дискуссия. 2011. - № 7(15). - С. 125-129.

2. Ребрикова Н.В., Колесникова О.В. Исследование рынка образовательных услуг: краткий обзор // Молодой ученый. - 2017. - № 14. - С. 417-420 [электронный ресурс]. -URL: https://moluch.ru/ archive/148/41577/ (дата обращения: 12.03.2018).

3. Волошин А.В. Формирование механизма повышения конкурентоспособности организаций высшего образования на рынке образовательных услуг: автореф. дис. ... канд. экон. наук. - Красноярск: СФУ, 2017. - 26 с.

4. Рыченков М.В., Рыченкова И.В., Киреев В.С. Исследование факторов, оказывающих влияние на выбор вуза абитуриентами, на различных этапах процесса поступления // Проблемы науки и образования. -2013 . - № 6 . -527 с. 